\title{
Research on the Effect of Imprecise Size Foam Samples on Acoustic Measurements in Impedance Tube
}

\author{
Chidhurappa Vamshi ,S.P. Jani
}

\begin{abstract}
Polymer foam materials are very commonly used acoustic materials for absorbing sound energy in noise control engineering, because of their higher porosity and light in weight. The acoustic characterization of these materials namely; absorption coefficient and transmission loss are measured using impedance tube, reverberation room method and intensity methods. Among these three impedance tube is the most popular method in laboratory condition. Here the sample size plays a main role in the accurate characterization acoustic materials by using the impedance tube. The present paper discusses effect of variation in the sample size on their acoustic measurements. The foam sample are prepared using Resistance wire foam cutter(RWFC). Their absorption coefficient and transmission loss for large and small samples with variations in sample dimensions are measured and compare with ideal dimension results. A detailed measured data and analysis are done to understand the effect of undersized and oversized foam samples on absorption coefficient and transmission loss results as a function of frequency. The results show that the variations in sample size has immense effect of measured results. The results presented in this study becomes a guideline for characterizing acoustic materials using impedance tube.
\end{abstract}

Keywords: Polymer foam, Foam cutter, Impedance tube, absorption coefficient and transmission loss

\section{INTRODUCTION}

Polymer foam materials are used as an acoustic treatment in engineering applications, for example, in rooms, buildings, studios, industries, workshops [1,2]. These materials have good acoustic absorption capability in low to medium frequency range. Apart from the sound absorption capability these materials can be made to adopt any complex shapes and thus becomes very robust solutions for sound absorption.

By using the acoustic foam materials residual sound can also be eliminated from all the space. These acoustic foams are made with polyurethane and they are light in weight. These materials can eliminate the echoes as well as background noise in the room. To characterize the properties of the foam materials i.e. the capability of sound absorption, reflection and transmission, can be measured using impedance tube. Depending upon the plane -wave propagation the tube categorized as Large and Small. The large tube covers the low frequency range from $64 \mathrm{~Hz}-$
Revised Version Manuscript Received on 10, September 2019.

Chidhurappa Vamshi, Department of Mechanical Engineering, Marri Laxman Reddy Institute of Technology and Management, Dundigal, Hyderabad, Telangana, India

S.P. Jani, Department of Mechanical Engineering, Marri Laxman Reddy Institute of Technology and Management, Dundigal, Hyderabad, Telangana, India(Email: spjani10@gmail.com)
$1600 \mathrm{~Hz}$, and small tube covers high frequency range from $800-6300 \mathrm{~Hz}$. Low frequency has the facility to measure $100 \mathrm{~mm}$ diameter sample, high frequency has $30 \mathrm{~mm}$ diameter facility. The higher frequency limit of these measurements depends on plane wave assumption and lower frequency limit depends on microphone spacing. To measure the acoustic characterization of these foam materials Impedance tube method [3] is used, where absorption coefficient and transmission loss of the material is measured in normal incidence in prescinded frequency range. There are few limitations to measure the samples in the impedance tube with frequency range [4]. The circumference of the tube plays important role which as noted earlier by Beranek, [5] while many researchers also state the microphone placing [6] and calibration [7] of the microphone varies the results of the prepared samples.

In this present paper the acoustic characterization absorption coefficient and transmission loss is carried out by using the impedance tube. Hot wire foam cutter system is developed to cut the foam materials to test the samples for large tube $102 \mathrm{~mm}, 100 \mathrm{~mm}, 98 \mathrm{~mm}$ and for small tube $32 \mathrm{~mm}$, $30 \mathrm{~mm}$ and $28 \mathrm{~mm}$, accordingly. These acoustic properties depend upon the size of the samples prepared which noted earlier by Kosten and J. H. Janssen, [8]. Even though many cutters available in the market for cutting the samples they are very expensive in cost and the capability of cutting the required size sample were not available. Due the change in the sample size the air gaps may take place and the results may be inaccurate which previously noted by Allard and Delage, [9] The main objective of this study is to develop a hot wire cutting system and to demonstrate the effect of sample size variations on acoustic characterization in impedance tube. This study becomes a basic guideline to prepare samples for acoustic characterization in impedance tube. 
Research on the Effect of Imprecise Size Foam Samples on Acoustic Measurements in Impedance Tube

\section{SAMPLES AND EXPERIMENTAL SETUP}

\subsection{Samples}

(A). Low frequency samples

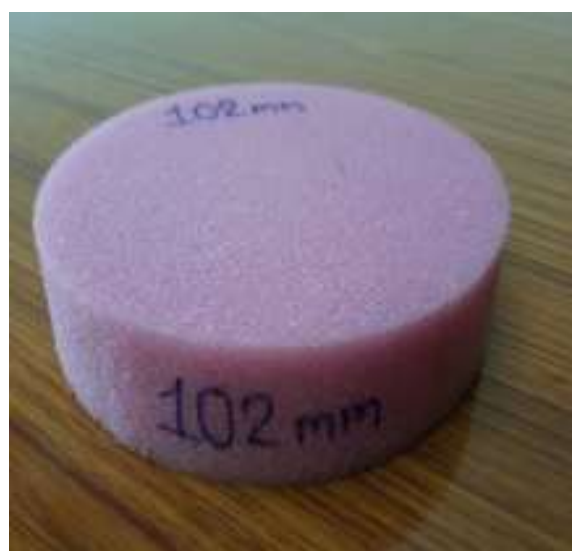

Fig.1. Test specimen of foam material with $102 \mathrm{~mm}$ diameter

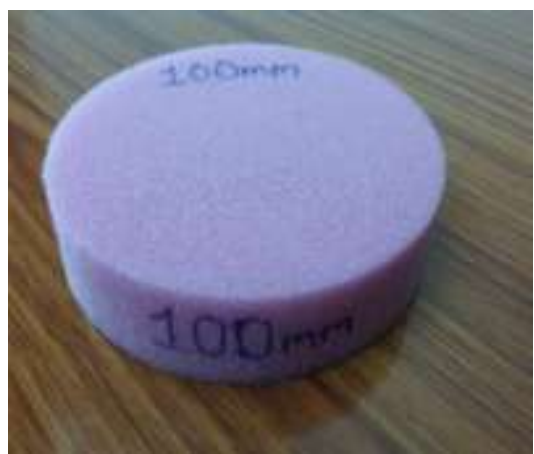

Fig. 2 Test specimen of foam material with $100 \mathrm{~mm}$ diameter

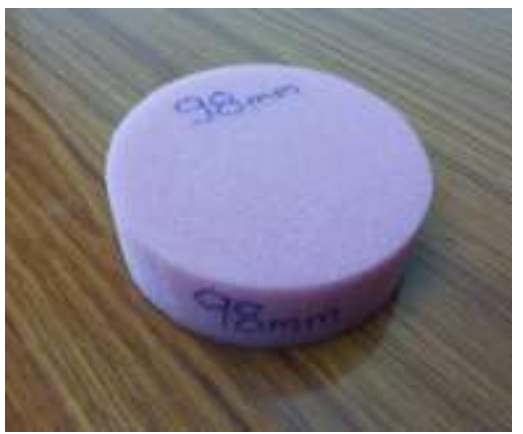

Details of samples preparation (all dimensions are in $\mathbf{m m}$ )

\begin{tabular}{|c|c|c|c|c|}
\hline \multirow[t]{2}{*}{ S.NO } & \multirow[t]{2}{*}{ Diameter } & \multirow[t]{2}{*}{ Thickness } & \multicolumn{2}{|c|}{ Frequency range of measurement } \\
\hline & & & Absorption & Transmission \\
\hline 1 & 102 & 25 & $63-1600 \mathrm{~Hz}$ & $63-1600 \mathrm{~Hz}$ \\
\hline 2 & 100 & 25 & $63-1600 \mathrm{~Hz}$ & $63-1600 \mathrm{~Hz}$ \\
\hline 3 & 98 & 25 & $63-1600 \mathrm{~Hz}$ & $63-1600 \mathrm{~Hz}$ \\
\hline 4 & 32 & 25 & $800-6300 \mathrm{~Hz}$ & $1600-6300 \mathrm{~Hz}$ \\
\hline 5 & 30 & 25 & $800-6300 \mathrm{~Hz}$ & $1600-6300 \mathrm{~Hz}$ \\
\hline 6 & 28 & 25 & $800-6300 \mathrm{~Hz}$ & $1600-6300 \mathrm{~Hz}$ \\
\hline
\end{tabular}

(B). High frequency samples

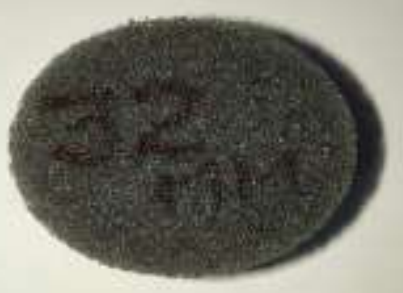
diameter diameter

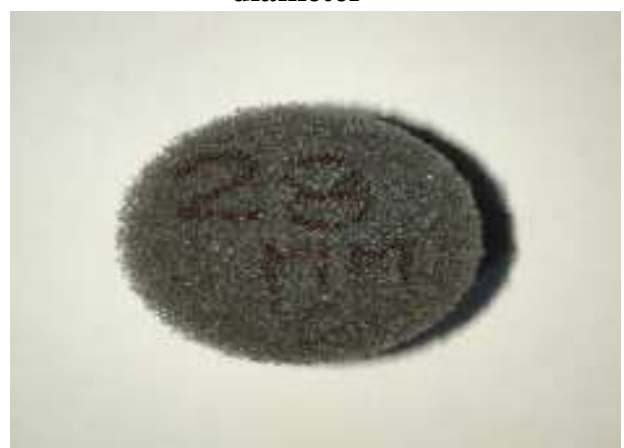
diameter

Fig.6 Test specimen of foam material with $28 \mathrm{~mm}$

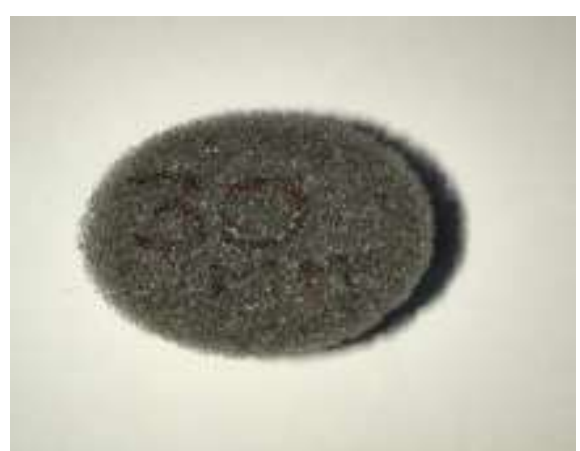

Fig.5 Test specimen of foam material with $30 \mathrm{~mm}$
Fig.4 Test specimen of foam material with $32 \mathrm{~mm}$ 
The above Table. 1 foam sample are prepared by using the Resistance hot wire foam cutter. The outlet of the foam cutter is first designed by using software i.e. CATIA V5, then manufactured by ply wood material according to required parameters. A motor with $15 \mathrm{rpm}$ is used to rotate the sample with the help of belt by using dc supply. One end is fixed to the shaft of the motor and another end to the shaft of the sample holder. Ni-chrome wire is adjusted to put the sample at different sizes to cut i.e. for low frequency $102 \mathrm{~mm}, 100 \mathrm{~mm}$ and $98 \mathrm{~mm}$ and for high frequency $32 \mathrm{~mm}, 30 \mathrm{~mm}$, and $28 \mathrm{~mm}$, respectively. Ni-chrome wire is heated with the temperature voltage of 0.51 volts, current with 1.26 amps with help of dc power source. Ni-chrome as shown in the figure. 7 . The ideal temperature and working parameters were identified by extensive experiments and parametric studies.

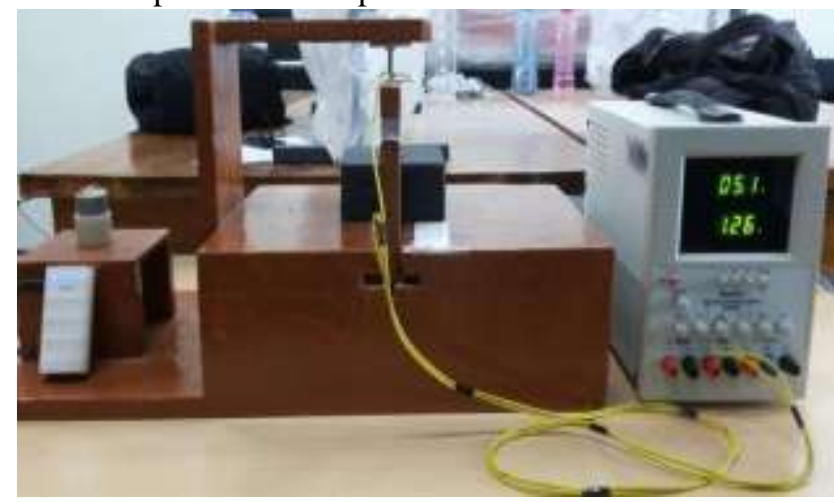

Fig.7 Sample preparation setup

\subsection{Experimental setup}

The acoustic characterization of the foam materials i.e. absorption coefficient [10,11] and transmission loss are measured using impedance tube set up as shown in Fig.8. (a) and (b). Reverberation room method and intensity methods, among these three, impedance tube is the most popular method in laboratory condition. Depending upon the plane -wave propagation the tube categorized has Large and Small. The large tube covers the low frequency range from $64 \mathrm{~Hz}-$ $1600 \mathrm{~Hz}$, and small tube covers high frequency range from $800-6300 \mathrm{~Hz}$. Low frequency has the facility to measure $100 \mathrm{~mm}$ diameter sample, high frequency has $30 \mathrm{~mm}$ diameter facility. Here the sample size plays a main role in the results to get the accurate measurements by using the impedance tube.

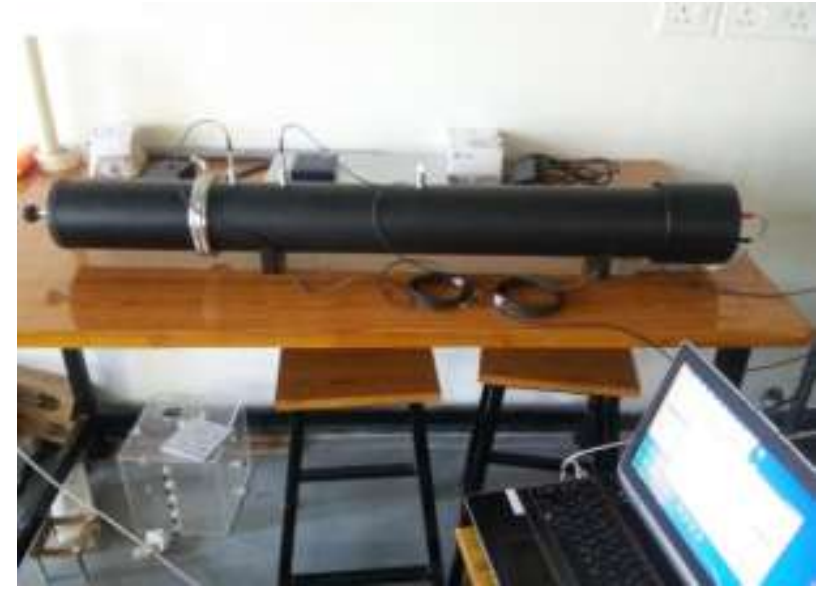

Fig. 8. (a) schematic diagram of impedance tube experimental setup Absorption coefficient

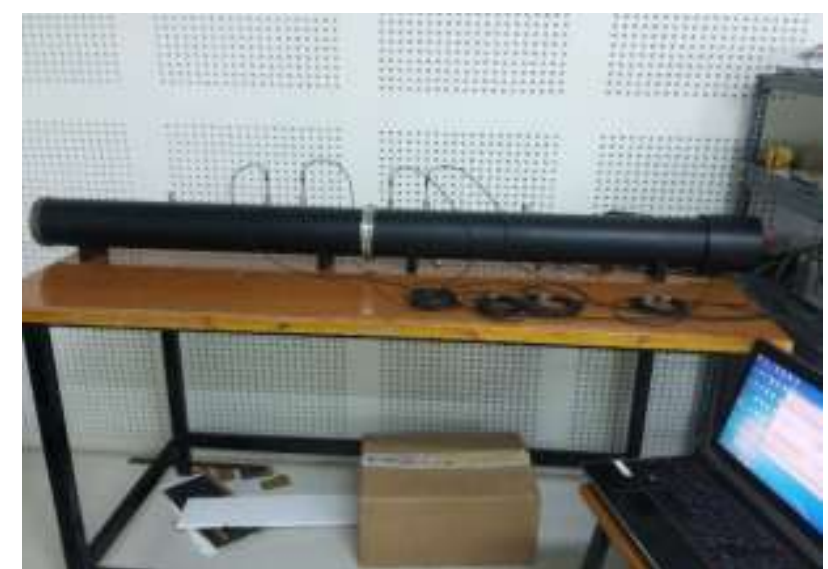

(b) schematic diagram of impedance tube experimental setup Transmission loss

These experiments are performed with the laboratory specification of temperature relative humidity with $25^{\circ} \mathrm{C}$ and $50 \%$, respectively. The speed of the sound is $343.2 \mathrm{~m} / \mathrm{s}$ and density of air was $1.2 \mathrm{~kg} / \mathrm{m}^{3}$. Impedance tube consist of one end with a loud speaker with $8 \mathrm{ohms}$, frequency range of 50 $\mathrm{Hz}-20000 \mathrm{~Hz}$, and with the termination of microphones. Another end with the rigid body of sample holder. The speaker is connected to produce the random signal with generator thus propagation of plane waves in the tube. The frequency of a plane wave [12] depends upon the internal diameter of tube size i.e. for small tube absorption coefficient and transmission loss is $800 \mathrm{~Hz}-6300 \mathrm{~Hz}$ (abs), $1600 \mathrm{~Hz}-$ $6300 \mathrm{~Hz}$ (TL). Two microphones were used at the provided length of the tube for absorption coefficient while four microphones were used for transmission loss. These microphones were connected to the data-acquisition system which further connected to the computer interface. The transfer function method was used to measure absorption coefficient and transmission loss of the samples. Calibration was done carefully for knowing the sensitivity of the microphones with the help of $114 \mathrm{~dB}$ (at $1000 \mathrm{~Hz}$ ) calibrator.

\section{RESULTS AND DISCUSSION}

This section emphasis on the measured results of prepared samples (mentioned in Table 1) in respective frequency ranges. The main objective of this section is to analyze experimental results of the sample configurations discussed in previous sections. The two microphone and four microphone impedance tube methods were used to estimate the acoustic absorption coefficient as well as transmission loss of the samples. Measurements were carried out at laboratory conditions where temperature and relative humidity were $290 \mathrm{C}$ and $50 \%$, respectively. The measurement method used follows ISO $1050-2$ as well as ASTM 1050-08.

Figure 9 and 10 shows the measured absorption coefficient and transmission loss of large samples in frequency range of 63-1600 Hz. Absorption coefficient results shows that as the diameter of sample reduces its absorption coefficient increases and vice versa. This is because as reduction in diameter causes clearance between the sample and tube

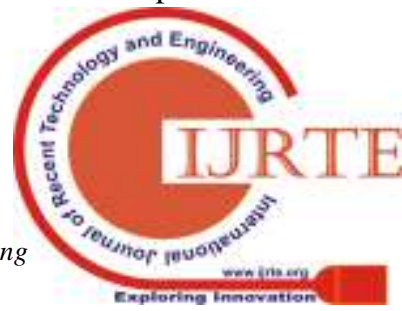


diameter leads to entrapped air. This entrapped improves the sample absorption coefficient and need to be avoided during measurements. However, this effect is more predominant at low frequency and less affected in higher frequency in case of small tube as shown in Fig. 11.

In contrast, the TL loss of undersized sample is less than that of oversized one. This is due to leakage around circumference of undersized sample. In addition, oversized sample has finite TL at lower frequency and achieving a minimum value (dip at a frequency) at certain frequency and again increasing. This finite TL is due to compression of sample around circumference leading to increase in stiffness and gives a finite TL at lower frequency. The dip in TL is a frequency corresponds to the shear resonance of sample at which sample transmits acoustic energy efficiently. The similar trend for TL is continued and observed in higher frequency region with small tube measurements and shown in Fig. 12.

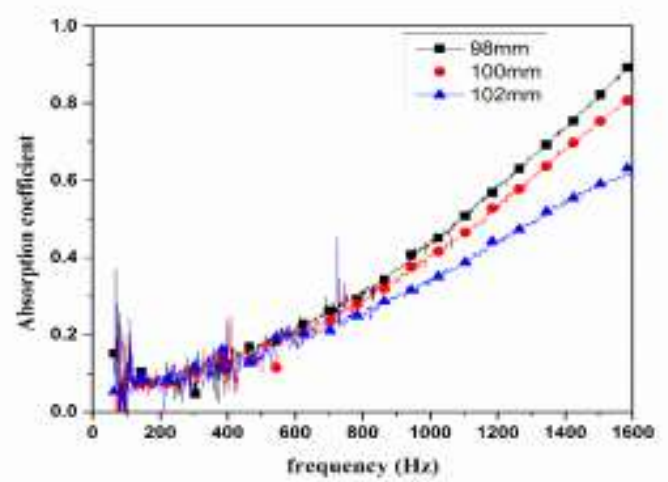

Fig.9. Comparison test for absorption coefficient with large tube samples

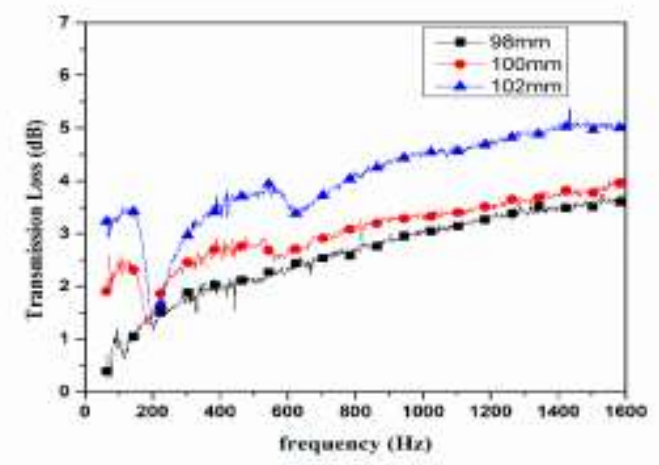

Fig.10. Comparison test for transmission loss with large tube samples

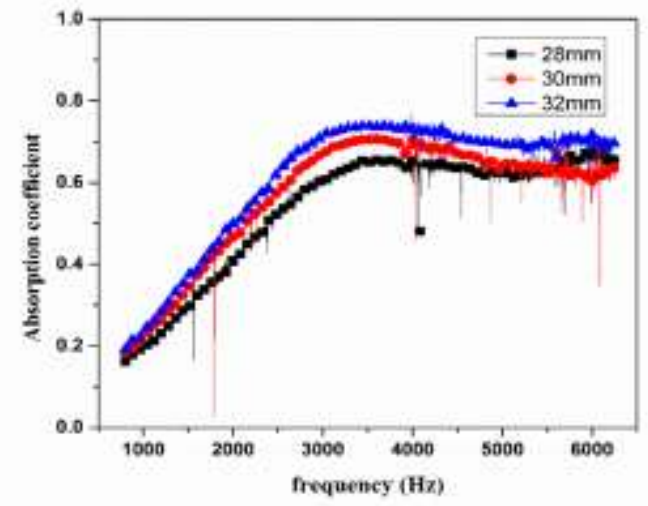

Fig.11. comparison test for absorption coefficient with small tube

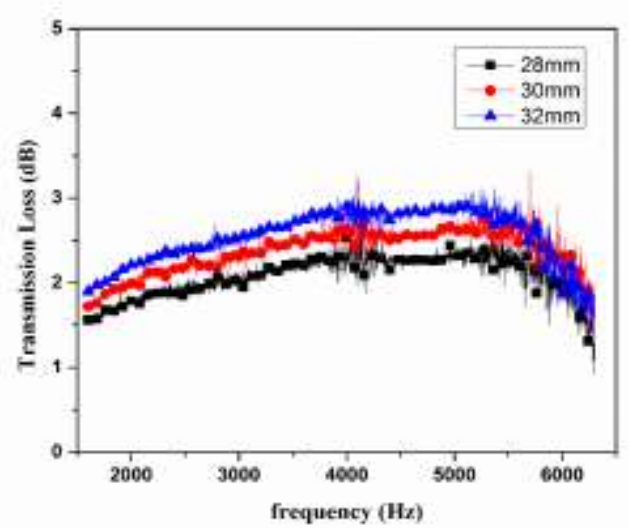

Fig.12. comparison test for transmission loss with small tube

\section{CONCLUSION}

In this study, a hot wire foam cutter (HWFC) has been developed. CAD modeling was done to achieve the final layout of hot wire foam cutter and used the same drawings for fabricating cutter. Three foam samples were cut with diameters of $98 \mathrm{~mm}, 100 \mathrm{~mm}$ and $102 \mathrm{~mm}$, for low frequency and $32 \mathrm{~mm}, 30 \mathrm{~mm}$ and $28 \mathrm{~mm}$ for high frequency respectively. It has been observed that the variations in sample size has immense effect on measured absorption coefficient and transmission loss. Hence, using exact dimension samples in impedance is necessary. The current hot wire cutter has the capability to achieve accurate circular sample dimensions. This study gives the basic framework to fabricate the samples for standard measurement techniques and helps to avoids mounting errors during measurements.

\section{REFERENCES}

1 Bies DA, Hansen CH. Engineering noise control: theory and practice. CRC press; 2009.

2 https://www.soundproofcow.com/product-category/soun d-absorption-materials/

3 "Acoustics-Determination of Sound Absorption Coefficient and Impedance in Impedance Tube-Part 2: Transfer Function Method", International Standard ISO 10534- 
4 "Standard Test Method for Impedance and Absorption of Acoustical Materials Using a Tube, Two Microphones and a Digital Frequency Analysis System", ASTM E 1050: 1998, American National Standards Institute, (1998).

5 L. L. Beranek, "Some notes on the measurement of acoustic impedance,' J. Acoust. Soc. Am. 19, 420- 427 (1947).

6 B.F.G. Katz, "Method to resolve microphone and sample location errors in the two-microphone duct measurement method", J. Acoust. Soc. Am., 108(5), 2231-2237, (2000).

7 R.Boonen,P.Sas,W.Desmet,W.LauriksandG.Vermeir,"Ca libration of the two microphone transfer function method with hard wall impedance measurements at different reference sections", Mech. Syst. Signal Pr., 23(5), 1662-1671, (2009).

8 C. W. Kosten and J. H. Janssen, "Acoustic properties of flexible and porous materials," Acustica 7, 372-378 $\sim 1957$ !.

9 J.-F. Allard and P. Delage, "Free field measurements of absorption coef- ficients on square panels of absorbing materials," J. Sound Vib. 101, 161-170 (1985)

10 ASTM, E1050-08 standard test method for impedance and absorption of acoustical materials using a tube, two microphones and a digital frequency analysis system, ASTM International, West Conshohocken, PA.

11 Koruk H. An assessment of the performance of impedance tube method. Noise Control Eng J 2014;62(4):264-74.

12 Munjal ML.Acousticsof ductsand mufflers.2nded.Chichester, UK:JohnWiley andSons; 2014. 